\title{
RELATO DE CASO - ESPOROTRICOSE FELINA: REINFECÇÃO É UMA REALIDADE?
}

\author{
(Case report - feline sporotricosis: is reinfection a reality?)
}

${ }^{1}$ Fernanda Paula da Silva Torres, ${ }^{1}$ Ingridy Fhadine Hartmann, ${ }^{2}$ Elizabete Balbino Javorouski, ${ }^{1}$ Cleber de Oliveira Lima, ${ }^{1}$ Poliana Vicente de Souza, ${ }^{1}$ Suzana Maria Rocha, ${ }^{1}$ Márcia Oliveira Lopes, ${ }^{1}$ Vivien Midori Morikawa

1Universidade Federal do Paraná, Curitiba, Paraná, Brasil. ²Secretaria Municipal de Saúde de Piraquara, Paraná, Brasil.

*Correspondência: silva.fer91@gmail.com

RESUMO: A esporotricose é uma doença de caráter zoonótico causada por espécies fúngicas do complexo Sporothrix. Os felinos domésticos desempenham um importante papel na epidemiologia da doença, uma vez que carreiam elevadas quantidades de células leveduriformes nas lesões cutâneas, bem como nas unhas e cavidade oral (SBMT, 2020). Neste contexto, o Departamento de Vigilância Sanitária da Secretaria Municipal de Saúde (DEVISA) da Prefeitura de Piraquara-PR monitora as notificações que chegam por meio de denúncias ou contato direto de tutores de animais suspeitos para a doença. Em 20 de fevereiro de 2018, foi atendido um paciente felino, fêmea, de dois anos de idade, não castrado e pesando $2,5 \mathrm{~kg}$, que apresentava lesões avermelhadas, ulcerativas e com exsudato purulento na região facial, com extensão próxima à região orbitária. Apesar da evidência das lesões cutâneas o animal não apresentava outras manifestações clínicas ou alterações fisiológicas relevantes. Durante a anamnese, a tutora relatou que os sinais haviam surgido há cerca de sete dias e que não havia outros contactantes felinos na residência, apesar do animal ter acesso livre à rua. O diagnóstico da esporotricose foi clínico-epidemiológico, iniciando-se, imediatamente, o tratamento via oral com o antifúngico Itraconazol na dose de $100 \mathrm{mg}$ por animal, uma vez ao dia, até a remissão total das lesões. Após 60 dias de tratamento, as lesões regrediram consideravelmente, confirmando o quadro sugestivo de esporotricose e, após quatro meses de tratamento, as lesões regrediram por completo. Entretanto, a fim de evitar recidivas, manteve-se a medicação por mais um mês, com alta em 23 de julho de 2018, sendo providenciada a castração pela Secretaria do Meio Ambiente da Prefeitura Municipal de Piraquara-PR. Após dois anos e dois meses de alta, a tutora notificou novamente o DEVISA, relatando novas lesões internas na região nasal, não por recidiva, considerando-se o tempo decorrido e a cura completa em 2018, mas pelo provável contato com outro animal infectado, uma vez que a tutora observou sinais de briga, pois o animal ainda possuía acesso livre à rua. Durante a avaliação clínica, constatou-se afecção do trato respiratório superior, com lesão tipo "nariz de anta", característico de infecção por fungos do complexo Sporothrix. O caso está sendo acompanhando e o animal encontra-se, novamente, em tratamento desde o dia 14 de setembro de 2020, utilizando-se o Itraconazol em associação com o lodeto de Potássio, na dose de 20 $\mathrm{mg} / \mathrm{kg}$, uma vez ao dia, tratamento este mais indicado por conta da afecção do trato respiratório superior (REIS, 2016). Apesar de laborioso, o tratamento precoce da esporotricose felina é eficiente, porém, animais com acesso livre à rua permanecem susceptíveis a reinfecções, como vem sendo observado pelo DEVISA Piraquara. Apesar dos esforços para conscientizar a população, a partir de orientações e assinatura do Termo de Compromisso para Animais em Tratamento de Esporotricose, a doença tem tido aumento significativo no município, demandando ações educativas permanentes de guarda responsável de animais.

Palavras-chave: guarda responsável; lesões cutâneas; zoonose.

Agradecimentos: Ao Departamento de Vigilância Sanitária da Secretaria Municipal de Saúde de Piraquara/PR, por ceder as informações necessárias que contribuíram para a elaboração deste relato de caso. 


\section{Referências}

REIS, E. G.; SCHUBACH, T. M. P.; PEREIRA, S. A. et al. Association of itraconazole and potassium iodide in the treatment of feline sporotrichosis: a prospective study. Medical Mycology, v. 54, n.7, p.684-690, 2016. Disponível em: <https://academic.oup.com/mmy/article/54/7/684/2222582>. Acesso em: 01/10/2020.

SOCIEDADE BRASILEIRA DE MEDICINA TROPICAL - SBMT. Esporotricose: número de casos deve aumentar e há risco de surto no País, alerta infectologista. 2020. Disponível em: < https://www.sbmt.org.br/portal/sporotrichosis-number-of-cases-should-increase-and-there-is-riskof-an-outbreak-in-the-country-warns-infectologist/>. Acesso em: 01/10/2020. 